\title{
CONSERVATION BEYOND CONSOLIDATION FOR PREHISTORIC MONUMENTS: FINDING NARRATIVES FROM ARCHAEOLOGY TO ARCHITECTURE FOR SCOTTISH BROCHS
}

\author{
CHANG LIU ${ }^{1 *}$, DIMITRIS THEODOSSOPOULOS ${ }^{2}$ \\ ${ }^{1}$ The Edinburgh School of Architecture and Landscape Architecture (ESALA) \\ The University of Edinburgh \\ 20-22 Chambers St, EH1 1JZ Edinburgh, UK \\ e-mail: Chang.liu@ed.ac.uk,www.chomliu.com (*corresponding author) \\ ${ }^{2}$ The Edinburgh School of Architecture and Landscape Architecture (ESALA) \\ The University of Edinburgh \\ 20-22 Chambers St, EH1 1JZ Edinburgh, UK \\ email: d.theodossopoulos@ed.ac.uk \\ www.eca.ed.ac.uk/architecture-landscape-architecture/dimitris-theodossopoulos
}

Keywords: Brochs, Prehistoric, Conservation, Consolidation, Narratives

\begin{abstract}
The sophisticated drystone Iron-Age brochs of Northern Scotland, called Complex Atlantic Roundhouses by archaeologists, have shown a relatively high technological culture. Their architectural conservation should strike a balance in presenting their key features (structure, materials, building use and architectural elements) in a concept of wholeness that integrates its major phases rather than design unity of a hypothetical original form. However, currently there is uncertainty due to the lack of agreement for a standard broch scheme and the need for more archaeological research. As most brochs in Scotland are fragile ruins and only a few of them have been scientifically explored, they have been conserved through basic consolidation for safety reasons in very localized methods, primarily by archaeologists. All of them are open to the public but only a few are developed as tourist sites. In both situations, none has shown the complete features of anything close to a standard typology as a narrative of their origin and a few have interpreted correctly the changes after Iron Age as narratives for modification. Significant conservation was conducted often before full archaeological excavations and did not lead to a satisfying architectural experience, so people still have a inconclusive image of brochs after a visit. This paper studies the brochs through their collective concept as a building typology rather than separate images of different sites. Conservation for brochs in Scotland could argue for modern holistic projects that go beyond consolidation, exporting narratives from archaeology to architecture.
\end{abstract}




\section{BROCH INTRODUCTION}

\subsection{Broch background}

A broch is an Iron Age drystone hollow-walled structural type built from $800 \mathrm{BC}$ to $250 \mathrm{AD}$ and found only in Scotland. However, due to the huge complexity of the building structure as well as the long un-evidenced history, their conservation encounters much difficulty as their archaeology can be very sporadic and controversial. Brochs are special monuments in Scotland for three main characteristics.

- Brochs are double-circular-wall complex round houses. This characteristic is outstanding because other Iron Age roundhouses in Europe do not have double-walls with walking passage inside and they are quite smaller. The broch not only demonstrated the understanding of circular space by those prehistoric communities, but also left much mystery for our society with further discoveries through archaeological excavations, dealing the sophistication of the Iron Age characteristics.

- Brochs are house types which are typically important to Scotland. Brochs are called 'Complex Atlantic Roundhouses' [1] which means complexity both in plans and elevation, always in drystone masonry. The structure has typically demonstrated the ability to survive in the Scottish climate and geographic conditions.

- Brochs as significant Iron Age drystone structures. The Iron Age is the final epoch of the three-age system, preceded by the Stone Age (Neolithic) and the Bronze Age, in the

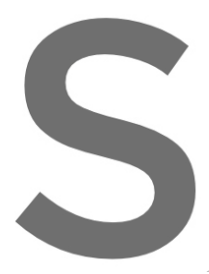
prehistory of Burope. The British Iron Age lasted in theory from the first of iron for tools and weapons in Britain to the Romanisation of the is land. A is typically local building materia even for now in the North of Scotland. The Royal Commission on the Ancient and Historical Monuments of Scotland identified a total of 571 candidate broch sites throughout the country [2]. Officially, there are 317 scheduled monument sites by Historic Environment Scotland (HES), which are designated Register for free at https/ WwW scipedjascom to diown load the version without the watermark there are 860 records of archaeological sites which are brochs or possible brochs. MacKie, the foremost Scottish scholar who had much academic contribution to the recording of brochs, has said that 'brochs are among the most striking of all the prehistoric monuments of Europe' [3]. In general, brochs are important ancient monuments to both Scotland and Europe.

Based on these records, this paper studies brochs broadly as a building typology rather than separate sites and, after reviewing the current range of their conservation approaches, argues for modern holistic conservation projects that go beyond the current practice of consolidation, exporting narratives from archaeology to architecture.

\subsection{The definition of broch}

Mackie [4] defined five main features across all brochs like 1) round plans, 2) thick walls, 3) size, 4) a ledge or scarcement on the inside wall face and 5) at least one of certain hollowwalled architectural features- classification of a site as a broch needs at least two of characteristics $1-4$ above and in addition No.5. Based on this, hundreds of brochs could be identified. However, due to the limited excavations or recordings, only the brochs with properly 
surveyed architectural plans are used for the statistical analysis in this paper. Based on the information provided by Tanja Romankiewicz [5] for around 120 surveyed monuments, there are no sites that look the same to another. Even the orientations of their entrance have no demonstration of any preferences on any directions. However, there are some similar features, like the staircases that are always going clockwise from ground floor to the upper floor.

Figure 1: The configuration of Revised Standard Model for Brochs [6]

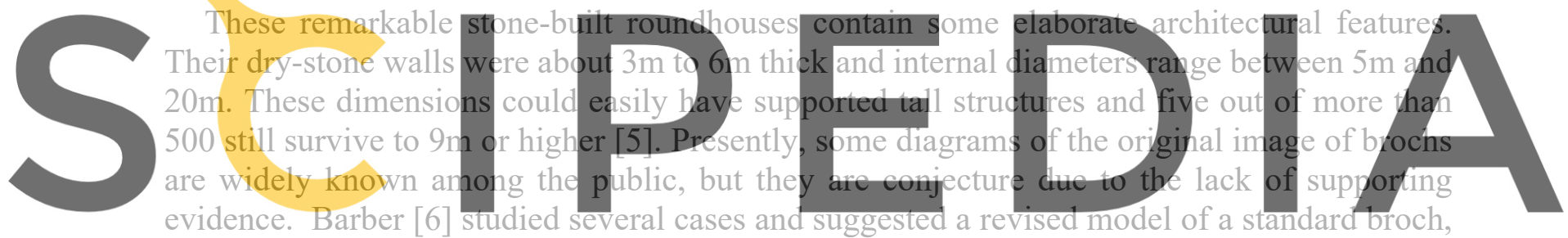
aiming to show they were all built to a standard canonical plan and their apparent diversity is a

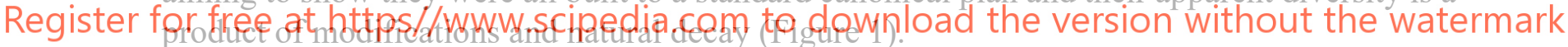

\section{BROCH CONSERVATION}

\subsection{Broch conservation situations}

Brochs are 'scheduled monuments' in Scotland which offer strict conditions for investigation, preservation, and recording of matters of archaeological or historical interest. A scheduled monument in Scotland is a nationally important archaeological site or monument which is given legal protection by being placed on a list (or "schedule") maintained by Historic Environment Scotland and is governed by the Ancient Monuments and Archaeological Areas Act 1979 [7].

Brochs are open to public visitors in Scotland. A few of them are well preserved like Mousa in Shetland, Midhowe in Orkney, and Dun Telve in Glenelg, which means usually surviving of clear shapes or certain heights, aspects that determine the public's view. The majority of brochs however are ruins of stones, very difficult to interpret by an untrained eye.

The most prominent conservation projects were done by unprofessional antiquarians who removed significant evidence to exhibit their own ideas of understanding a broch. For example, one of the first brochs explored with the intention of obtaining and publishing useful 
information seems to have been the Howe of Hoxa on South Ronaldsay, Orkney, investigated by George Petrie in 1848. The clearing out of Backies broch near Golspie in Sutherland is equally memorable, and after visited by J. J. Worsaae in 1848 sketches were made that are the earlier known records of those works [4]. From 1890 to 1901, Sir Francis Tress Barry, an English businessman and antiquarian, excavated more than 10 brochs. However, Barry's excavation was limited by techniques and some of brochs were not fully excavated, which led to artefacts removal and an absence of evidence recorded [6]. Therefore, a long process of defining the origin for each roundhouse is apparently inevitable.

Even earlier changes in brochs are evident but these can be identified as essential modifications of the original design during the archaeological study. For example, Mousa, known as the tallest and most complete broch in Scotland, is assumed to have been modified by a Norseman who completed the staircase up to the parapet [8]. This created a slightly overhanging upper part of the tower, which does not appear in the other four tall brochs as Dun Telve, Dun Troddan, Dun Carloway, and Dun Dornaigil (Fig. 2). Since Mousa is the most complete surviving monument, it set a stereotype for the general public

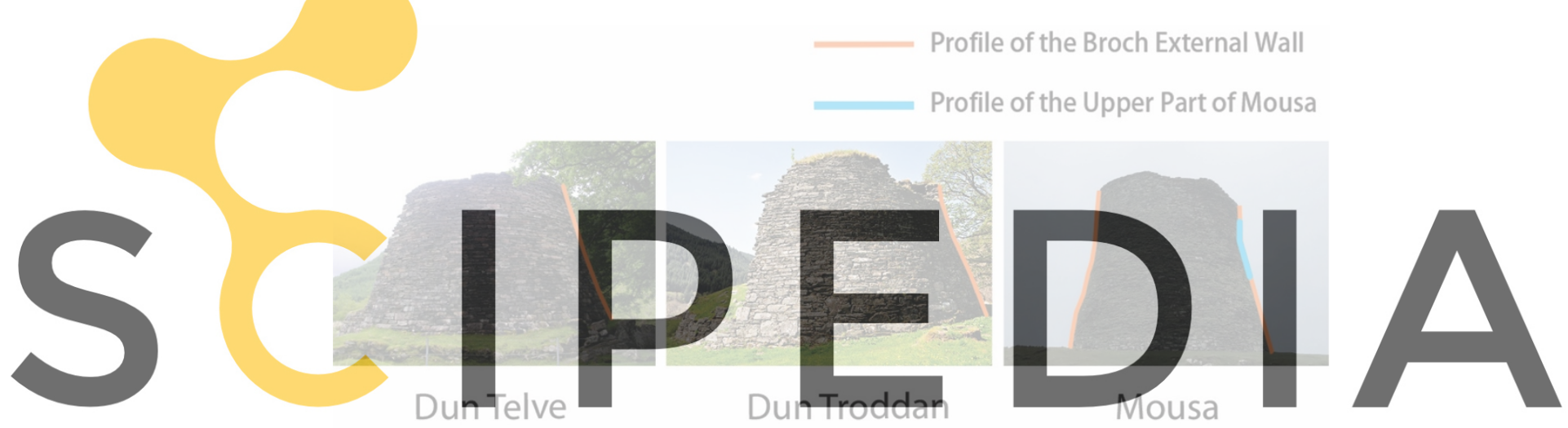

Register for free at https//www.scipedia.com to download the version without the watermark

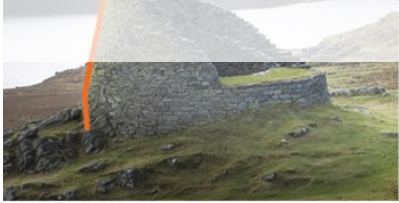

Dun Carloway

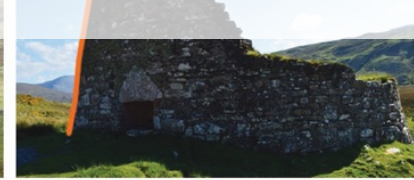

Dun Dornaigil

Figure 2: The profile study of Dun Telve, Dun Troddan, Dun Carloway and Dun Dornaigil.

At present, due to extensive legislation by HES protecting ancient monuments, much less external damage is expected. But brochs, as monuments with complex architectural features and controversy in dating, deserve deeper considerations for their conservation compared to other, historic monuments where the origin of buildings were documented, to make their restoration meaningful. At present any restoration attempt is conservative primarily repairs and consolidation for safety reasons in very localized areas, primarily by archaeologists, as most of them are fragile ruins and only a few have been scientifically explored. 
As seen in Figure 3, an example of the recent practice is Clachtoll, where the entrance was consolidated firstly and after archaeological excavation in 2018 the staircase was dismantled and reassembled and all rubble at the interior was removed. The best-preserved tall brochs, like dun Telve, though have been strengthened in undocumented campaigns so the extent of repairs is difficult to ascertain. Gurness is a case where dating was misinterpreted or ignored (phases that never co-existed were presented together) while Midhowe restoration actually brought back features that the earlier clearing of the ruins had cancelled (edge-set slabs applied as external buttresses against the $\mathrm{N}$ face of the broch wall) [6].

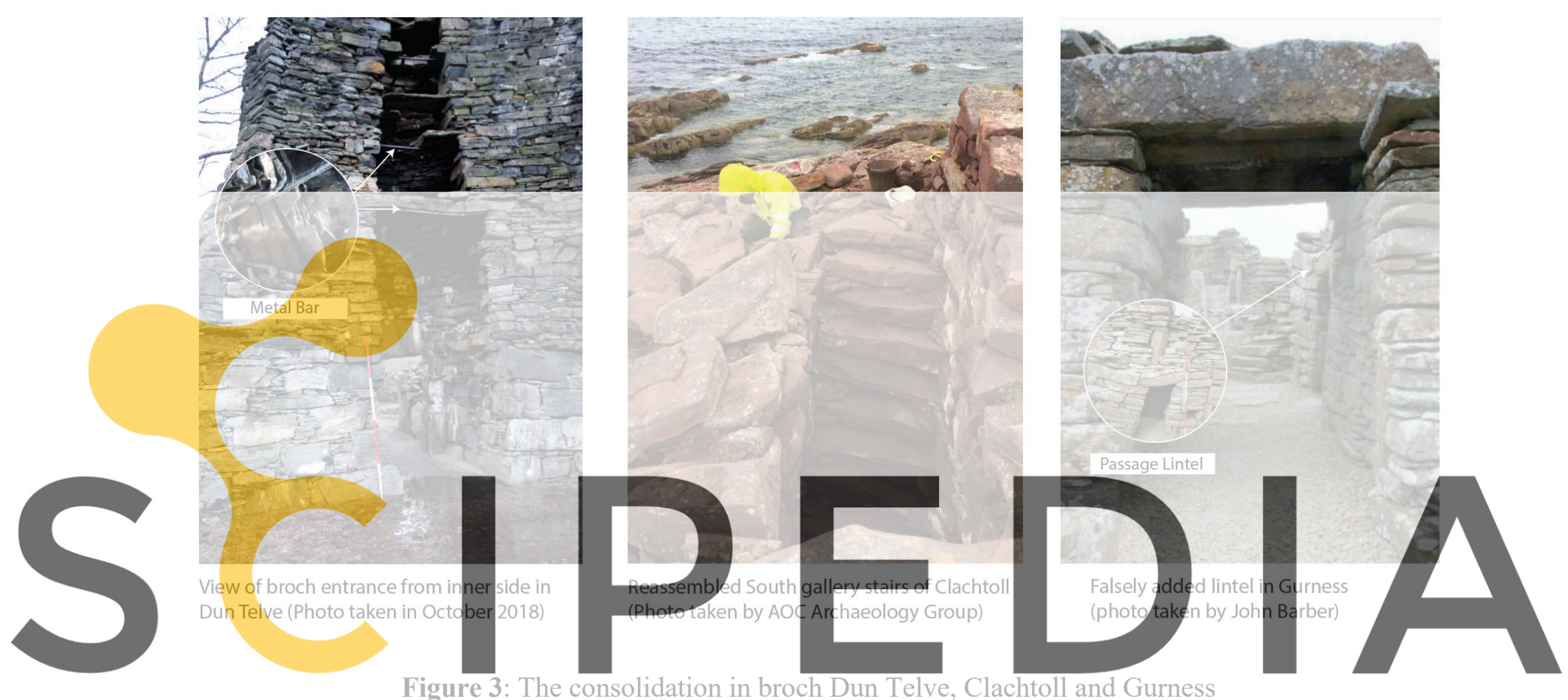

Register for free at https//www.scipedia.com to download the version without the watermark Generally, the brochs conservation should work with the archaeology. The archaeological research would offer an understanding of the building and architectural conservation should inform future archaeological excavations. What happened to brochs, damage, or repair, if identified with a date, has already become a historic event that needs to be considered in conservation planning.

This is not in general too different to practice elsewhere in prehistoric towers in Europe. The earlier nuraghe in Sardinia, for example, has invariably undergone interventions of fallen debris clearance, wellhead consolidation, and protection, rehabilitation of the staircase, removal of harmful past repairs, general re-integration of the fabric through partial reconstructions, etc (see the cases of Palmavera, Majore, Ola, and Funtana). Temporary shoring and interior clearance have also been the usual practice in the talaiots as Bronze Age megaliths on the islands of Menorca and Majorca.

Broadly speaking, the monuments at present convey two meanings: their original design idea and later modifications by people from different times. Being architectural structures, the need for narratives is also investigated, in an attempt to enhance the sense of wholeness through architectural experience. 


\subsection{The need for narratives}

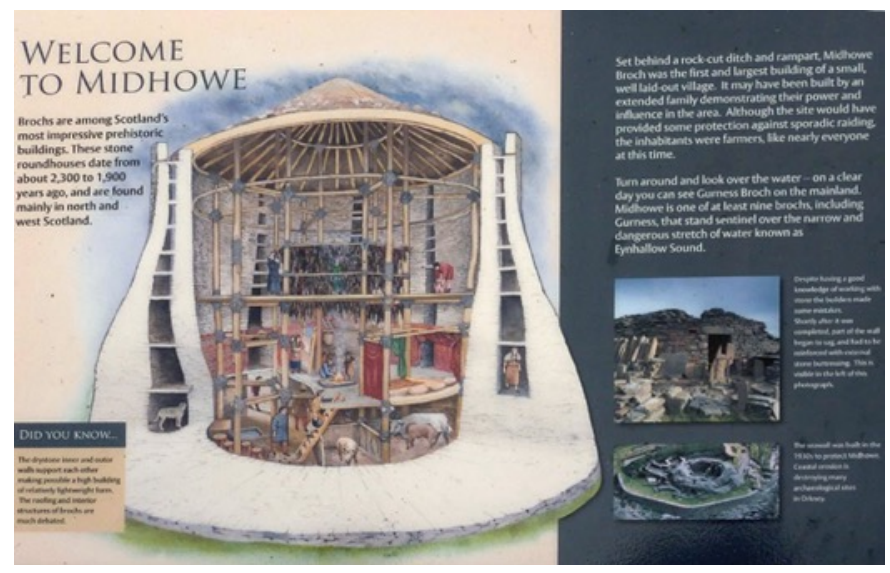

Figure 4. The schematic board for Midhowe broch in Orkney.

The image of how a broch looks like has been spread to social media nowadays, but it cannot represent all the brochs. For example, Figure 4 is one of the general images found on websites or TV programs speculating on human life in brochs. Most of the images like this are based on basic concepts like perfectly circular brochs built on even ground with constant galleries at several levels which endbled conabitation 11 where the animas irve-an the ground floor an people in the upper floors. An immediate observation is that in of them built on a slope

form is only a conjectur

Besides the five talle:
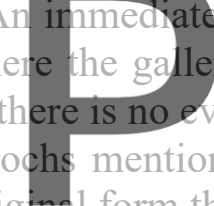

obviously different in the
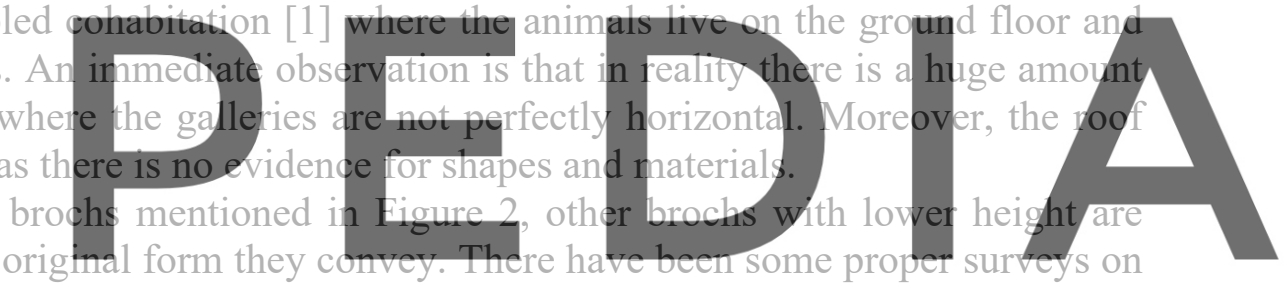

brochs done by professional archaeologists and this research is looking at a collection of such

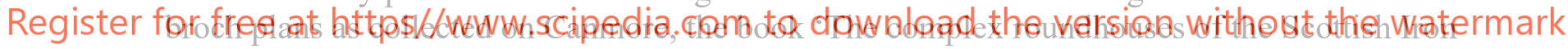

Age: an architectural analysis of complex Atlantic roundhouses (brochs and galleried duns),

with reference to wheelhouses and timber roundhouses' written by Tanja Romankiewicz [5] and the survey "The roundhouses, brochs, and wheelhouses of Atlantic Scotland c.700 BC-AD 500: architecture and material culture" written by Euan W. MacKie [4]. Also, archaeological reports published in the recent 10 years offered surveys of Thrumster and Nybster which are included in the data pool. 


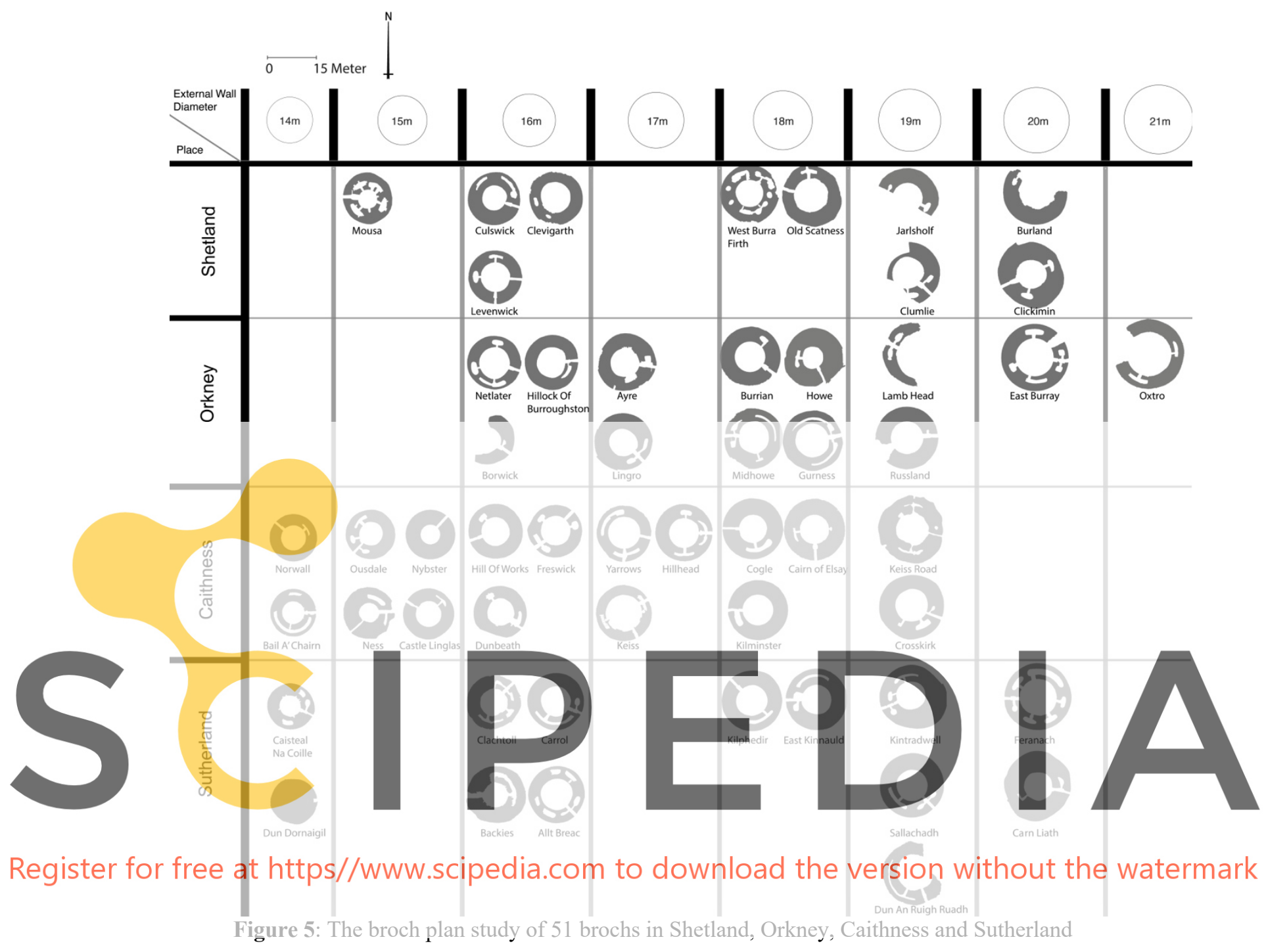

The plans of 51 brochs, which were professionally surveyed, are selected and divided into groups based on their locations to study their design concept in multiple manifestations and adaptations as seen in Figure 5. The building parameters are mainly overall sizes, the external wall diameters of these brochs vary from $13 \mathrm{~m}$ to $22 \mathrm{~m}$. The largest one, as Thrumster in Caithness, is almost double the size of the smallest one (Norwall). The other important parameter is circularity. The brochs in Caithness are much more circular-shaped except Keiss Road and Thrumster due to their incomplete survived shapes, while there are ellipse-shaped brochs like Backies and Carn Liath. Also, in terms of broch entrance, unlike other Iron age monuments which would normally face the East, the point of the day where sun is rising from, or south for the most sunlight, brochs' entrances are quite diverse. Even in some location group, brochs do not share a dominant direction. It indicates the ancient builders did not respond to the four cardinal directions, representing sunlight and shadows. Also, some brochs had two entrances, possible due to reuse in later times (like Yarrows), 
There are more variations in features like stacked voids, shape of lintels, the stone type of course and bond type, and so on. The monuments are not some reproduced models of a typical building but some works following a precise idea, a way of arranging living space and a combination of feasible construction skills. Considering the different level of collapse and damage on sites, each of them is so unique being in the collection of this complex house types. Each broch does not offer much about the concepts to be understood easily, while a combination of brochs would express the idea. This paper suggests the idea of seeing the monument concepts and strategies for designs through a collection and a spectrum of different sites, rather than a precise looking of one building object.

As the recent consolidation taking dominant places, the study of ancient building concepts moderates this conservative situation and stimulate the sites to express ideas rather than just the presence.

\section{CONSERVATION OF PROCH RUINS}

\subsection{Theory: the 'wholeness' of 'ruins'}

Firstly, the broch remains should be treated as a whole building. Cesare Brandi [9] has much emphasized the aesthetic value of the work saying 'once that artistic nature is lost, nothing but a relic remains'. Hence, the restoration should aim to re-establish the potential oneness of the work of art, as long as this is possible without committing artistic or historical forgery, and without erasing every trace of the passage through time-in the work of art. The importance to attribute the character refers to the whole, and been parts of the origin archaeological park as the Brochs are impressive, which is much about
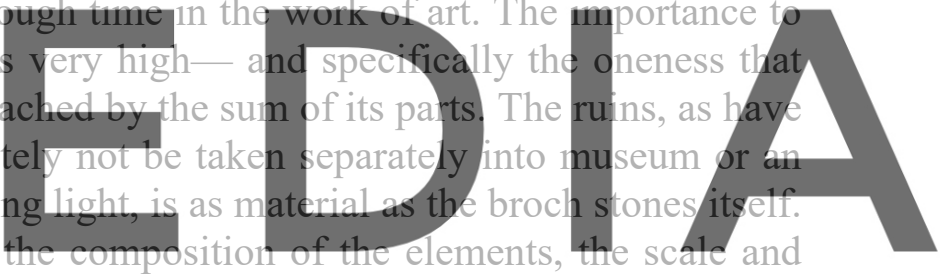

location of the buildings. Dry sandstones, or parts of the broch, can exhibit the culture of the

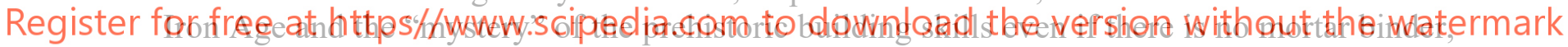
which often indicates a certain industrialisation of the building trades. The architectural values of prehistoric houses require the wholeness of building, which provides the architectural experience to the human beings.

At the present, the wholeness of the brochs Scotland is ruined in most cases. The 'wholeness' of the original is missing while the later modification become a new part of the whole. A.M. Oteri [10] mentioned the ruins as "what remains" (of a construction, in our case) things become more complicated and our interest in ruins is not only an aesthetic interest, like the beauty of massive stones in Angkor Wat. Ruins are usually not as appreciated by people as restored historic monuments. If the ruins cannot be visited by people, at least for sightseeing, the ruins would normally have no other function and become so called 'dead monuments'

However, the consolidation of broch ruins is actually expecting to turn an old stone ruin into a newly repaired ruin, where conserved ones are still weak in demonstrating an architectural work. A readable ruined site should be better for people to understand. Thus, the conservation should go beyond the consolidation to find narratives for brochs to interpret the builders' ideas. 


\subsection{Consolidation dealing with structural problems}
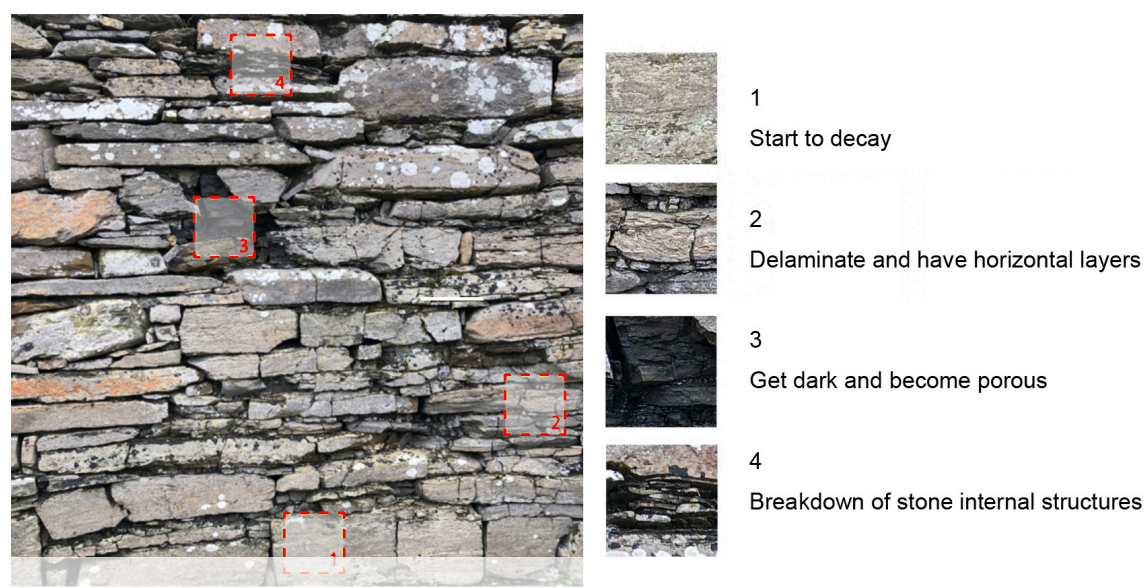

Figure 6: The dry-stone analysis of broch Midhowe.

Consolidation is definitely needed for long-existing monuments as the structures would become quite fragile to collapse due to its material decay. As Figure 6 displays, the Orkney flagstone used in Midhowe in Rousay is sandstone, which is a sedimentary rock. Based on the observation of the broch, different levels of decay conditions appear on facade. In some brochs

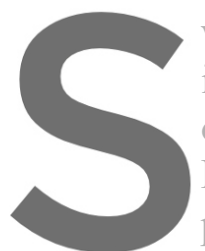
which survived to a dertain height, porous std inner galleries and chan or future archaeological excavations, it has to be Mousa, the interior and exterior wall faces w passages were fixed even with steel structures

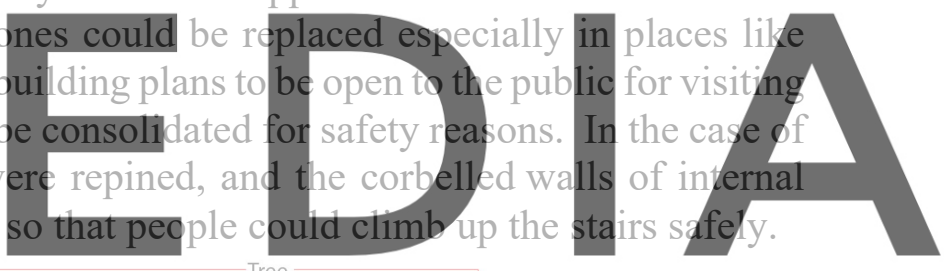

Register for free at https//www.scipedia.com to download thelle version without the watermark

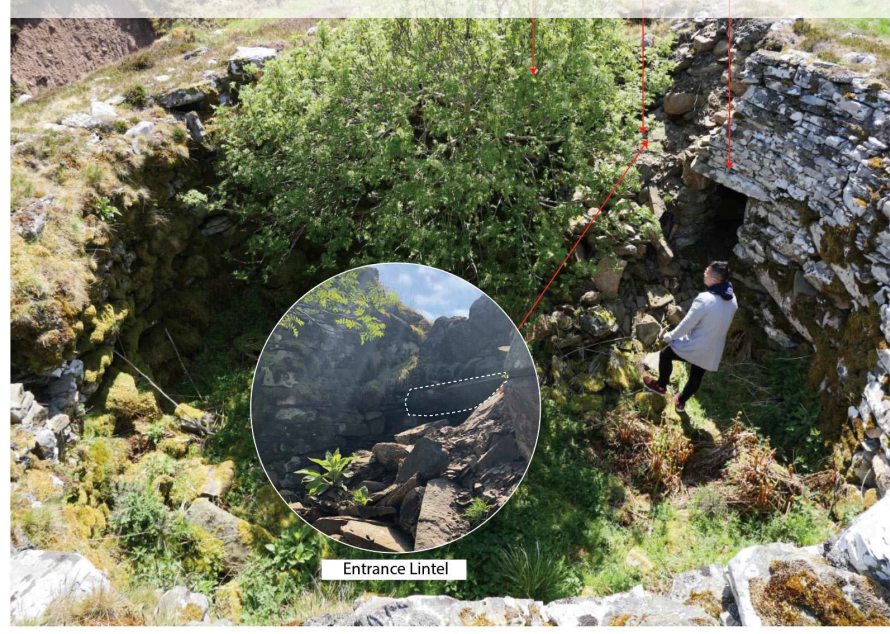

Ousdale broch before consolidation (Photo taken in April 2018)

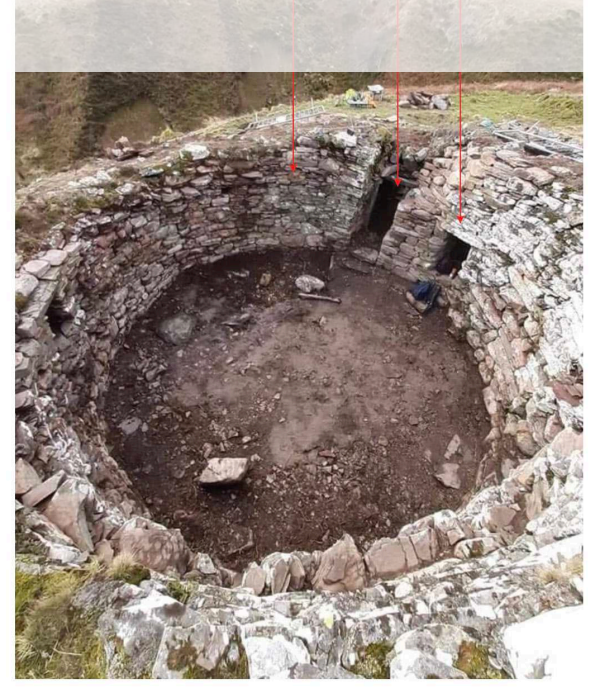

Ousdale broch after consolidation (Photo taken in April 2020)

Figure 7: The consolidation of broch Ousdale 
In broch Ousdale which is an unusual broch embedded in the ground that has been heavily damaged (Figure 7), the tree growing at the wellhead collapse was removed to clear the entrance and the stones on the ground were reused to rebuild a part of the inner wall. The consolidation work is definitely needed, where partial collapse happens and causes structural problems. Even steel structures could be used to stabilize tilted walls after the stones repined.

\subsection{Interpretive conservation}

The conservation of an ancient monument like a broch is to protect its architectural, historic, and archaeological values. However, the conservation of brochs could be more than that and can stress the concept of their design to make them readable and offer an architectural experience both for public and researchers. Completing architectural features can offer a precise delimitation of space, like the low and narrow galleries showing there were possibly not many people using them at the same time. These features, if existing in a whole broch, could be highlighted to archaeologists to imagine the possible activities and frame the use of the artefact found on sites. This would require the conservation of broch to be interpretive. The interpretive conservation and it has two levels of meaning:

1) Correct past conservation errors if later scientific research proved them wrong.

2) Clarify features if they are confusing.

Correcting the errors mainly aims to keep pace with the present archaeology research which may disprove the previous statements which have already influenced the finished conservation

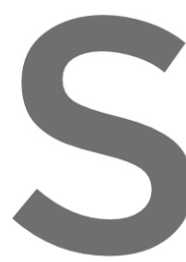
project, like the case of quite important for per difference through a

The scarcement in a broch means the stones support a raised annular floor and perhaps scarcements judging from the five tall brochs,

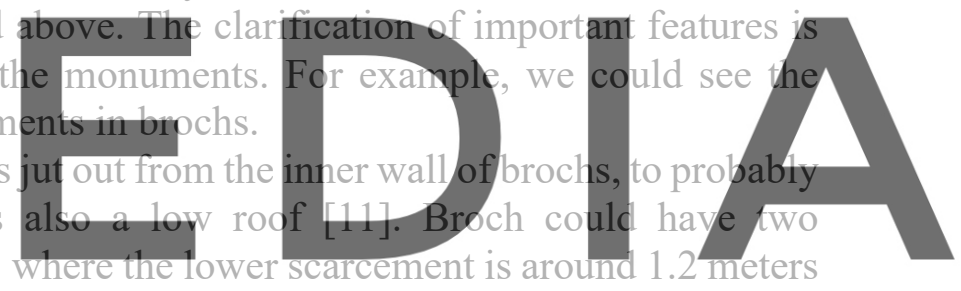
above ground and higher scarcement is near the wall head (Figure 8). A scarcement is usually

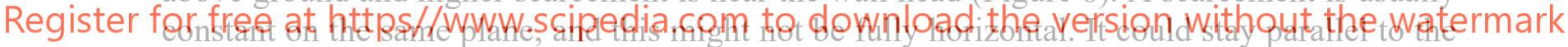
sloping ground, like in the case of Caisteal Grugaig. The low scarcement would make floor area at least double, which is much related to the need to build stairs going up, and the high scarcement would make the roof possible.

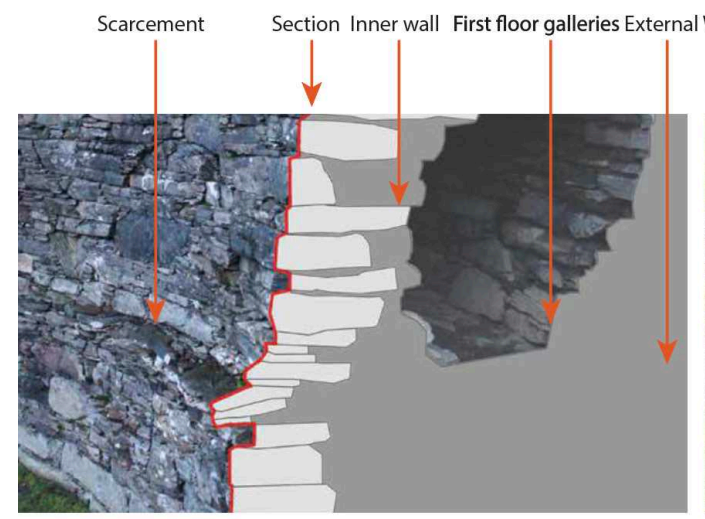

The section of Dun Troddan

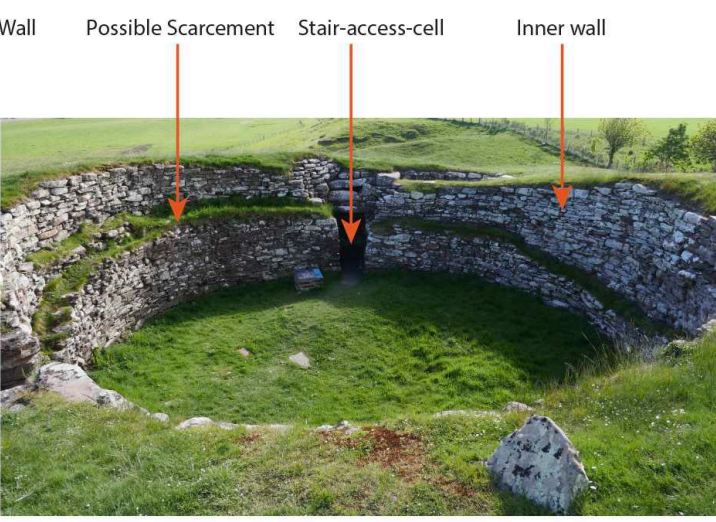

The view of the inner wall in Carn Liath

Figure 8. The section of Dun Troddan and the view of inner wall in Carn Liath 
Compared to Figure 1, the curved 'possible scarcement' in Figure 8 in the inner wall circle in Carn Liath is sort of misleading. which is different from brochs nearby, like Ousdale and Dunbeath. The site was proved to be occupied in the Bronze Age before a broch was built [12]. As it was suggested as scarcement by Mackie [13], however, John Barber [6] found the scale errors in drawings which failed to find the proper position of the inner wall face. He proved that the curved scarcement was either caused by the structural failure, or by the reconstruction of the tower at and above that level which was returned. Therefore, the origin of scarcement is either lost or covered in the 'possible scarcement' which is actually an inner lining wall face built attached to the real inner wall face. Therefore, the dimensions and scarcement features of the conserved broch Carn Liath offer wrong images of this type.

If the additional inner lining wall face could be removed which accepts this result of scarcements missing, people might still agree that a broch without clear scarcement is still a broch, as the existing building is original. Like in the broch of Jarlshof, only half of the broch has survived due to the coastal erosion, while it has shown the clear and proper broch features

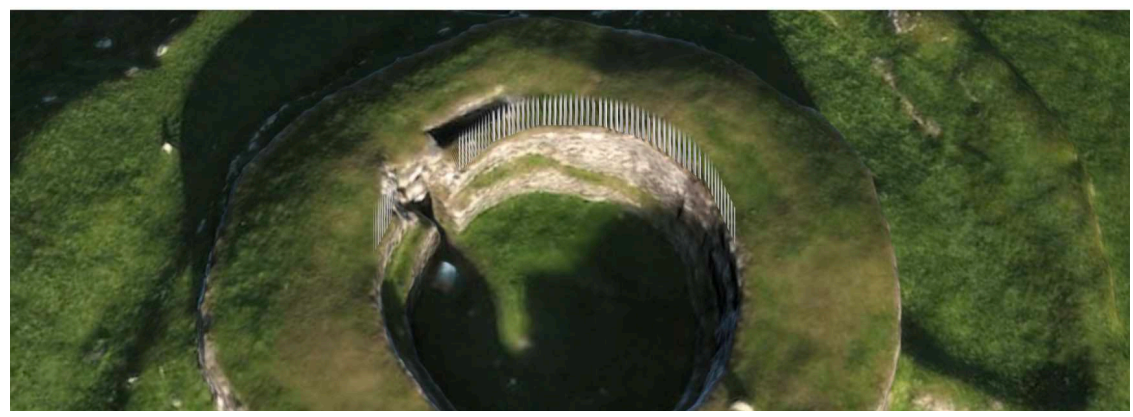

Figure 9. Steel bars highlight the original inner wall face in Carn Liath

If more evidence or findings are needed to confirm the changes in the conserved sits, a mark on the wrong parts of brochs should be possible. Removable structures, like steel bars as seen in Figure 9, could be used to make up the collapsed parts and the original wall head of inner wall, which could offer the impression of the function of the building elements and the sense of building scale without damaging the archaeological site. However, under the concept of being interpretive, there would be a question about what level of impact should this approach reach. In Article 9 of the Venice Charter, it stated that 'any extra work which is indispensable must be distinct from the architectural composition and must bear a contemporary stamp' [14], which stressed the importance of respect for original material and authentic documents. For brochs here, the authenticity lies in the ruins and the archaeological values should have priority to be considered. The interpretive conservation for brochs should not repair them with the same sandstones as being confusing or fake. Importantly, the added materials should always be removable to get rid of damages caused by improper conservation decisions.

Generally, the architectural features could be seen as the choices the original builders made when they were designing. Some features are quite subtle showing their thoughts or attitudes towards the environment. The brochs could not be understood properly if the integrity of the features among all the brochs were not well studied and thus lead to a loss of richness in design. The interpretive conservation would focus much on the origin of brochs, therefore, the correction of mistakes in unprofessional excavations or consolidation and clarification of 
important features have become necessary. This would allow possible misjudgments in archaeology research at present and in the future as the reversible changes on prehistoric sites would mainly eliminate misunderstandings caused by modification and conservation.

\section{CONCLUSIONS}

The architectural features could be seen as the choices the original builders made when they were designing. The origin of brochs as rich designs and architectural spaces would ask for more interpretive works on ruined sites. The current range of conservation for brochs in Scotland could argue for modern holistic conservation projects that go beyond consolidation to find narratives for the building concepts from archaeology to architecture for Scottish brochs.

Acknowledgements. We thank our colleagues in Prokalo event from Edinburgh School of Architecture and Landscape Architecture for their comments

\section{REFERENCES}

[1] Harding, D. W. The Iron Age in Northern Britain Celts and Romans, Natives and Invaders. London: Routledge (2004). pp.161.

[2] Armit, I. Towers in the North: The brochs of Scotland. Stroud, Tempus (2003). ISBN 07524-1932-3. pp.16.

[3] Hedges, J. \& Bell, B. That tower of Scottish prehistory-the broch. Antiquity (1980), 54(211), pp.87-94.

[4] MacKie, E.W. The roundhouses, brochs and wheelhouses of Atlantic Scotland c.700 BCAD 500 : architecture and material culture, Oxford: Archaeopress (2002). pp 9, 31.

[5] Romankiewicz, T. The complex roundhouses of the Scottish Iron Age : an architectural analysis of complex Atlantic roundhouses (brochs and galleried duns), with reference to wheelhouses and timber roundhouses, Oxford: Archaeopress (2011).

[6] Barber, J. Approaching the mind of the builder: analysis of the physical, structural and social constraints on the construction of the broch towers of iron age Scotland (2017), PhD thesis, University of Edinburgh.

[7] "The Ancient Monuments and Archaeological Areas Act 1979." Antiquity 53, no. 209 (1979): 219-22..

[8] Fojut, N "Is Mousa a broch?" Proc Soc Antiq Scot 111. (1981) pp.220-228.

[9] Brandi, C, 1965. Theory of restoration. (2005). Roma: Firenze: Istituto centrale per il restauro; Nardini.

[10] Oteri A., Ruins and Design: dialogues over Times, Conservation/Transformation , Essegraph, Genova (ITA), (2011), pp. 361-374, ISBN: 978-2-930301-50-1.

[11] MacKie, E.W. The Leckie broch, Stirlingshire: an interim report. Glasgow Archaeological Journal (1982), 9(9), pp.60-72

[12] MacSween, Ann; Sharp, Mick. Prehistoric Scotland. New Amsterdam. (1989) p. 57. ISBN 071346173X.

[13] MacKie, E. W. The Roundhouses, Brochs and Wheelhouses of Atlantic Scotland c. 700 $B C-A D 500$ Vol 2 Part 1. Oxford, British Archaeological Reports. (2007).

[14] International Council of Monuments Sites. The Venice Charter: 1964-1994 = La Charte de Venise., Paris: International Council of Monuments and Sites. (1994). 